Revista Brasileira do Esporte Coletivo - v. 3. n. 2. 2019.

Artigo de revisão

\title{
O DESENVOLVIMENTO MOTOR DE CRIANÇAS DE 3 A 6 ANOS NA EDUCAÇÃO INFANTIL APLICADO A EDUCAÇÃO FÍSICA ESCOLAR
}

${ }^{1}$ Rennan Regys dos Santos Silva; ${ }^{2}$ berê Caldas Souza Leão; ${ }^{3}$ Dayana da Silva Oliveira

\section{RESUMO}

Introdução: A Educação Física Escolar é entendida como uma base para o conhecimento da cultura corporal, utilizando-se de movimentos para desenvolver progressos no processo educativo e motor do estudante. As aulas de Educação Física infantil são as primeiras vivências de atividades que desenvolvem habilidades, capacidades e qualidades físicas sem deixar de lado a exploração do lúdico, pois é de fundamental importância no ensino aprendizagem da criança. O desenvolvimento motor é um processo de aquisição e aumento da complexidade do movimento que um indivíduo possui. Na infância essa progressão é percebida com maior facilidade, onde a criança progredirá, aos poucos, de um movimento mais simples para um mais complexo. Objetivo: Identificar por meio de revisão bibliográfica o papel da Educação Física no desenvolvimento motor de escolares de 3 a 6 anos de idade. Método: $O$ presente estudo foi uma revisão bibliográfica, de abordagem qualitativa acerca do desenvolvimento motor de escolares do ensino infantil, de idades entre 3 a 6 anos. A pesquisa de dados foi realizada nas bases de dados Scielo, Biblioteca Virtual de Saúde (BVS), Pubmed e periódicos CAPES. Resultados e Discussão: A Educação Física no ensino infantil possibilita uma melhora no desenvolvimento motor de crianças de 3 a 6 anos, visto que as atividades motoras propostas principalmente por um profissional da Educação Física e realizadas por essas crianças, visam 0 desenvolvimento e a aprendizagem de movimentos futuros. Conclusão: A Educação Física como disciplina na Educação Infantil, se mostrou importante para o desenvolvimento motor das crianças de 3 a 6 anos. Nessa fase os aspectos cognitivos, afetivos e sociais da criança precisam ser estimulados e a Educação Física, por meio de ferramentas de ensino aprendizagem, pode proporcionar ao educando esse estímulo de forma prazerosa e eficaz.

Palavras-Chave: Desenvolvimento Motor, Educação Física Escolar, Ensino Infantil. 


\section{The motor development of children aged 3 to 6 years in pre-school education applied to physical education}

\section{ABSTRACT}

Introduction: School Physical Education is understood as a basis for the knowledge of the body culture, using movements to develop progress in the student's educational and motor process. The Physical Education classes for children are the first experiences of activities that develop abilities, abilities and physical qualities without leaving aside the exploration of the playful, since it is of fundamental importance in the teaching of the child. Motor development is a process of acquiring and increasing the complexity of movement that an individual possesses. In childhood this progression is perceived more easily, where the child gradually progresses from a simpler movement to a more complex one. Objective: To identify through literature review the relevance of Physical Education in the motor development of schoolchildren from 3 to 6 years of age. Method: The present study was a bibliographical review of a qualitative approach about the motor development of preschool children aged 3 to 6 years. The data search was performed in the databases Scielo, Virtual Health Library (VHL), Pubmed and CAPES journals. Results and Discussion: Physical Education in children's education allows an improvement in the motor development of children from 3 to 6 years, since the motor activities proposed mainly by a Physical Education professional and performed by these children, aim at the development and learning of future movements. Conclusion: Physical Education as a discipline in Early Childhood Education, was shown to be important for the motor development of children aged 3 to 6 years. At this stage the cognitive, affective and social aspects of the child need to be stimulated and Physical Education, through teaching teaching tools, can provide the student with this stimulus pleasantly and effectively.

Key words: Motor Development, Physical School Education, Early Childhood Education.

1 Graduado no Curso de Licenciatura em Educação Física da Universidade Federal de Pernambuco Centro Acadêmico de Vitória. ${ }^{2}$ Docente do Curso de Educação Física da Universidade Federal de Pernambuco- Centro Acadêmico de Vitória. ${ }^{3}$ Universidade Estácio de Sá- Recife.

E-mail: 1regysrennan@hotmail.com; 2iberecaldas@gmail.com; 3day.silvaef@hotmail.com

\section{INTRODUÇÃO}

A Educação Física Escolar é entendida como uma base para o conhecimento da cultura corporal, utilizandose de movimentos para desenvolver progressos no processo educativo e motor do estudante, onde ele poderá aprender e reproduzir posteriormente o conhecimento adquirido. Assim, a área de Educação Física hoje contempla múltiplos conhecimentos produzidos e usufruídos pela sociedade a respeito do corpo e do movimento. Entre eles, se consideram fundamentais as atividades culturais de movimento com finalidades de lazer, expressão de sentimentos, afetos e emoções, e com possibilidades de promoção, recuperação e manutenção da saúde. (BRASIL, 1997, p.23).
Dentre os objetivos da Educação Física Escolar, deve-se ressaltar a importância da estimulação dos estudantes a serem sujeitos participativos, autônomos e aptos a agir e pensar, contribuindo assim para a formação pessoal do aluno. Ao nos referirmos ás aulas de Educação Física no Ensino Infantil, isto não significa um espaço reservado exclusivamente ás crianças que possuem bom desempenho, ou de um professor que tem intenção de formar atletas precoces, mas, sim, de aulas que proporcionam novas experiências de movimento, em que o aluno possa se integrar socialmente, desenvolver seus domínios cognitivos, motores e afetivos, com possibilidades de criar, de tomar decisões, de avaliar e de conhecer as suas potencialidades.

(NISTA-PICCOLO; MOREIRA, 2012, p.33).

O Desenvolvimento motor é todo um processo pelo qual $\mathrm{o}$ indivíduo adquire e 
amplia a partir do seu nascimento. "O brincar das crianças é o modo primário pelo qual aprendem sobre seus corpos e potencialidades de movimento" (GALLAHUE; OZMUN; GOODWAY, 2013). São nos primeiros anos de idade que esses desenvolvimentos motores são percebidos mais facilmente, movimentos como andar, correr e saltar são alguns que tem uma grande importância no desenvolvimento motor da criança. "Nessa fase há um aumento de força muscular e ganho de habilidades motoras tanto simples como complexas" (NISTAPICCOLO; MOREIRA, 2012, p. 42).

$\mathrm{O}$ interesse pelo tema proposto parte da observação do crescente desenvolvimento motor de crianças da segunda infância, onde a Educação Física é uma grande aliada para que esse processo de desenvolvimento de habilidades seja contínuo e sempre melhorado.

O tema abordado está diretamente ligado à área de atuação do profissional de Educação Física, e tem uma grande relevância na vida acadêmica do pesquisador, onde os principais temas analisados contribuem para o conhecimento. Outros fatores a serem considerados são: o desenvolvimento da questão cognitiva, afetiva e social, que estão interligadas ao desenvolvimento global dessas crianças de 3 a 6 anos de idade.

Assim questiona-se como a literatura apresenta 0 desenvolvimento motor de escolares no ensino infantil, e como as aulas de educação física escolar podem contribuir para esse processo.

\section{REVISÃO DE LITERATURA}

As aulas de Educação Física infantil são as primeiras vivências de atividades que desenvolvem habilidades, capacidades e qualidades físicas sem deixar de lado a exploração do lúdico, pois é de fundamental importância no ensino aprendizagem da criança. Mas para uma aprendizagem adequada, é preciso um trabalho eficaz dos professores de Educação Física o qual se apoia no conhecimento do processo de desenvolvimento e aprendizagem para então poder atuar de uma maneira direta, oportunizando para as crianças a exploração dos movimentos fundamentais condizentes com 0 seu desenvolvimento (PANSERA; PAULA; VALENTINI, 2008).

Dessa forma a educação física pode contribuir muito para que os objetivos da Educação Infantil sejam alcançados, onde as propostas educacionais feitas pela Educação Física visam o desenvolvimento motor do aluno, utilizando o lúdico, que propende mais ao divertimento que a qualquer outro objetivo (NISTA-PICCOLO; MOREIRA, 2012, p.19).

Sendo assim o desenvolvimento motor de escolares no ensino infantil apresenta uma melhora na sincronização dos elementos temporais e espaciais dos movimentos, mas, são ainda geralmente restringidos ou exagerados, embora melhor coordenados. É caracterizado pela eficiência mecânica, coordenação e execuções controladas, somente possuindo algumas restrições as atividades que envolvem acompanhamento e interceptação de objetos (MIRANDA; AFONSO, 2014).

O desenvolvimento motor é um processo de aquisição e aumento da complexidade do movimento que um indivíduo possui. Na infância essa progressão é percebida com maior facilidade, onde a criança progredirá, aos poucos, de um movimento mais simples para um mais complexo. A Educação Física no ensino infantil possibilitará uma melhora no desenvolvimento motor de crianças, visto que as atividades motoras propostas principalmente por um profissional da Educação Física e realizadas por essas crianças, visam o desenvolvimento e a aprendizagem de movimentos futuros.

Ressalte-se que os fatores que afetam a aquisição de habilidades motoras constituem-se também os que são manipulados no ensino de habilidades motoras, motivo pelo qual os resultados de pesquisa têm forte apelo prático no sentido de fornecer sugestões ou de suscitar novas ideias de ensino a serem testadas no campo da intervenção profissional (TANI, 2016).

Compreendemos, então, que a Educação Física tem uma função fundamental na Educação Infantil, pela possibilidade de proporcionar às crianças uma diversidade de experiências através de situações nas quais elas possam criar, inventar, descobrir movimentos novos, reelaborar conceitos e ideias sobre 0 movimento e suas ações (BASEI, 2008, p. 01).

Portanto, a aula de Educação Física oportunizará para as crianças a exploração dos movimentos fundamentais condizentes com o seu desenvolvimento, transmissão dos benefícios da cultura corporal, proporcionando ao aluno explorar o seu corpo através da diversidade de movimentos que podem vivenciar, do contato corporal com os outros, oportunizando a ele que aprenda sobre si mesmo, sobre o mundo e possa fazer uso da corporeidade. Para o referido estudo, diante 
do que foi descrito anteriormente, objetiva identificar por meio de revisão bibliográfica o papel da Educação Física no desenvolvimento motor de escolares de 3 a 6 anos de idade.

\section{MÉTODO}

O método utilizado foi de pesquisa indireta, que tem como característica a utilização de informações, conhecimentos e dados já coletados por outras pessoas e demonstrados de diversas formas. Segundo Andrade (2001), método é o conjunto de procedimentos utilizados na investigação de fenômenos e o caminho para a chegar à verdade ou alcançar determinados fins ou objetivos. Portanto, o presente estudo foi uma revisão bibliográfica, que segundo Thomas; Nelson; Silverman, (2012), consiste na avaliação crítica de pesquisas sobre determinado tema. De abordagem qualitativa acerca do desenvolvimento motor de escolares do ensino infantil, de idades entre 3 a 6 anos.

A pesquisa de dados foi realizada nas bases de dados scielo, biblioteca virtual de saúde (BVS), assim como no, periódicos CAPES. $E$ os termos "Desenvolvimento motor", "Ensino infantil" e "Educação física Escolar" foram utilizados como descritores, combinados por meio dos operadores lógicos AND/OR.

Os critérios de inclusão utilizados, foram: artigos da língua portuguesa, publicados no período de 12 anos (20072019). Artigos incompletos, indisponíveis e que não estavam de acordo com a temática, foram excluídos do presente estudo.
Foi realizada uma pesquisa mediante todas as possibilidades de combinação entre os seguintes descritores: "Desenvolvimento Motor" (1), "Ensino Infantil" (2) e "Educação Física Escolar" (3), utilizando as bases de dados Scielo, Biblioteca Virtual de Saúde (BVS) e periódicos CAPES. Na base de dados Scielo a combinação 1 e 2 resultou em 11 artigos encontrados, 2 e 3 resultou em 7 e 1 e 3 foram achados 10 artigos. Na BVS, a combinação 1 e 2 resultou em 34 artigos descobertos, 2 e 3 resultou em 31 e 1 e 3 foram 21 artigos. No CAPES a combinação $1 \mathrm{e}$ 2 resultou em 50 artigos, 2 e 3 resultou em 198 artigos e 1 e 3 foram 75. Ao todo foram encontrados 437 artigos, desses artigos foi realizada a leitura dos títulos e resumos dos artigos que abordavam a temática em questão.

Em seguida foi realizada a aplicação dos critérios de exclusão, e o quantitativo de artigos final chegou a 8 , onde foi realizada uma leitura completa dos artigos e elaboração de fichamentos para utilização dos mesmos na construção do presente estudo. Foi elaborado um quadro síntese dos estudos encontrados sobre desenvolvimento motor em escolares de 3 a 6 anos (Quadro 1).

Quadro 1 - Quadro síntese dos estudos encontrados no referido estudo sobre desenvolvimento motor em escolares de 3 a 6 anos.

RESULTADOS E DISCUSSÃO

\begin{tabular}{|c|c|c|c|c|}
\hline $\begin{array}{l}\text { Autor } \\
\text { (ano) }\end{array}$ & Objetivos & $\begin{array}{c}\text { Teste de } \\
\text { avaliação }\end{array}$ & Resultados & Conclusão \\
\hline $\begin{array}{l}\text { Rodrigues } \\
\text { et al., } \\
\text { (2013). }\end{array}$ & $\begin{array}{l}\text { Verificar os efeitos } \\
\text { de diferentes } \\
\text { contextos no } \\
\text { desenvolvimento das } \\
\text { habilidades motoras } \\
\text { fundamentais e no } \\
\text { crescimento } \\
\text { somático de crianças } \\
\text { no ensino infantil. }\end{array}$ & TGMD-2 & $\begin{array}{l}\text { Nenhuma diferença foi } \\
\text { observada entre os } \\
\text { grupos de crianças. Mas } \\
\text { no final do ano letivo, } \\
\text { crianças que tiveram } \\
\text { atividades com o o } \\
\text { professor da sala } \\
\text { apresentaram redução no } \\
\text { nível de atividade física, } \\
\text { enquanto que crianças }\end{array}$ & $\begin{array}{l}\text { O envolvimento em } \\
\text { diferentes contextos } \\
\text { de aulas de educação } \\
\text { física não é suficiente } \\
\text { para promover } \\
\text { alteração somática } \\
\text { em crianças ao longo } \\
\text { do ano letivo. } \\
\text { Entretanto, educação } \\
\text { física com o professor }\end{array}$ \\
\hline
\end{tabular}




\begin{tabular}{|c|c|c|c|c|}
\hline & & & $\begin{array}{l}\text { com educação física com } \\
\text { o professor especialista } \\
\text { apresentaram } \\
\text { manutenção no nível de } \\
\text { atividade física e melhor } \\
\text { desenvolvimento das } \\
\text { habilidades motoras. }\end{array}$ & $\begin{array}{l}\text { especialista melhora } \\
\text { o desenvolvimento } \\
\text { das habilidades } \\
\text { motoras } \\
\text { fundamentais e } \\
\text { promove manutenção } \\
\text { do nível de atividade } \\
\text { física em crianças no } \\
\text { ensino infantil. }\end{array}$ \\
\hline $\begin{array}{l}\text { Saraiva, } \\
\text { Rodrigues } \\
\text { e } \\
\text { Barreiros. } \\
\text { (2011). }\end{array}$ & $\begin{array}{l}\text { Realizar um teste em } \\
\text { crianças de } 3 \text { a } 6 \\
\text { anos de idade, de } \\
\text { diferentes escolas } \\
\text { públicas. }\end{array}$ & $\begin{array}{l}\text { PDMS-2 } \\
\text { As propriedades } \\
\text { psicométricas } \\
\text { das Escalas } \\
\text { Peabody } \\
\text { Developmental } \\
\text { Motor II }\end{array}$ & $\begin{array}{l}\text { - Os resultados foram } \\
\text { expressos em } 3 \text { estudos, } \\
\text { o primeiro foi o estudo da } \\
\text { sensibilidade ao } \\
\text { desenvolvimento, onde } \\
\text { os resultados foram } \\
\text { melhorando de acordo } \\
\text { com que faixa etária } \\
\text { aumentava. O segundo, } \\
\text { estudo mostrou uma boa } \\
\text { estabilidade entre as } \\
\text { crianças. E o terceiro } \\
\text { estudo, a validade de } \\
\text { construto, não existiu } \\
\text { valores baixos em } \\
\text { nenhuma faixa etária, } \\
\text { todos os resultados foram } \\
\text { de bons a excelentes. }\end{array}$ & $\begin{array}{l}\text { A versão utilizada se } \\
\text { revelou como um } \\
\text { instrumento preciso e } \\
\text { válido para avaliar as } \\
\text { habilidades motoras } \\
\text { finas e globais das } \\
\text { crianças portuguesas } \\
\text { em idade pré-escolar. }\end{array}$ \\
\hline $\begin{array}{l}\text { Roweder } \\
\text { e Schmitt } \\
\text { (2016). }\end{array}$ & $\begin{array}{lr}\text { Identificar } & \text { as } \\
\text { contribuições } & \text { da } \\
\text { Educação } & \text { Física } \\
\text { para a Educação } \\
\text { Infantil a partir da } \\
\text { visão } & \text { dos } \\
\text { professores } & \text { que } \\
\text { atuam } & \text { em } \\
\text { instituições da rede } \\
\text { pública da cidade de } \\
\text { Porto Belo/SC. }\end{array}$ & $\begin{array}{ll}\text { Aplicação de } \\
\text { questionário. }\end{array}$ & $\begin{array}{l}\text { - De acordo com os } \\
\text { dados adquiridos nesta } \\
\text { pesquisa é possível } \\
\text { conhecer e analisar a } \\
\text { formação acadêmica, a } \\
\text { atuação profissional e a } \\
\text { opinião dos professores } \\
\text { da Educação Infantil } \\
\text { sobre a importância da } \\
\text { Educação Física para a } \\
\text { Educação Infantil. }\end{array}$ & \begin{tabular}{|lr} 
Nessa fase & os \\
aspectos cognitivos, \\
afetivos, motores e \\
sociais da criança \\
precisam \\
estimulados. \\
Educação Física, por \\
meio de elementos \\
do lúdico, pode \\
proporcionar ao \\
educando \\
estímulo de forma \\
prazerosa e eficaz.
\end{tabular} \\
\hline $\begin{array}{l}\text { Almeida } \\
\text { et al., } \\
\text { (2007). }\end{array}$ & $\begin{array}{lr}\begin{array}{l}\text { Avaliar } \\
\text { desenvolvimento }\end{array} & \text { o } \\
\text { motor e } & \text { as } \\
\text { características } & \\
\text { psicossociais } & \text { de } \\
\text { crianças } & \text { com } \\
\text { indicadores } & \text { de } \\
\text { dificuldades } & \text { na } \\
\text { aprendizagem } & \\
\text { escolar. } & \end{array}$ & $\begin{array}{l}\text { Escala de } \\
\text { Desenvolvimento } \\
\text { Motor, } \\
\text { Questionário } \\
\text { Psicossocial }\end{array}$ & $\begin{array}{l}\text { Dos escolares avaliados } \\
\text { apresentaram índices de } \\
\text { "Normal médio" à } \\
\text { "Normal baixo", do total } \\
\text { de escolares avaliados, } \\
\text { apresentaram média de } \\
16 \text { meses de atraso } \\
\text { motor em relação à idade } \\
\text { cronológica - (idade } \\
\text { negativa). } 5 \text { escolares } \\
\text { ficaram abaixo dos } \\
\text { demais, os maiores } \\
\text { déficits foram nas áreas } \\
\text { de esquema corporal, } \\
\text { organização espacial e } \\
\text { organização temporal. }\end{array}$ & 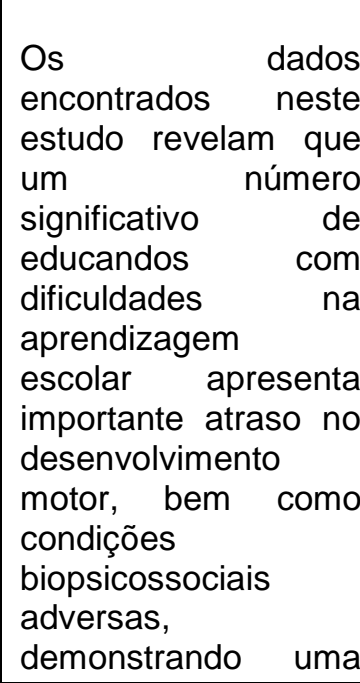 \\
\hline
\end{tabular}




\begin{tabular}{|c|c|c|c|c|}
\hline & & & & $\begin{array}{l}\text { possível relação entre } \\
\text { estes fatores. }\end{array}$ \\
\hline $\begin{array}{l}\text { Nunes, et } \\
\text { al., } \\
\text { (2014). }\end{array}$ & $\begin{array}{l}\text { Identificar o perfil } \\
\text { físico, bem como os } \\
\text { níveis de ansiedade, } \\
\text { motivação e atenção, } \\
\text { de estudantes nos } \\
\text { anos iniciais com } \\
\text { baixo rendimento } \\
\text { escolar. }\end{array}$ & $\begin{array}{lr}\text { Avaliação física } \\
\text { e imagem } \\
\text { corporal; } \\
\text { Avaliação } \\
\text { motivação, } \\
\text { ansiedade } \\
\text { atenção. }\end{array}$ & $\begin{array}{l}\text { Foi visto que algumas } \\
\text { medidas poderão afetar } \\
\text { as crianças futuramente, } \\
\text { as doenças } \\
\text { cardiovasculares, pelo } \\
\text { fato de alguns níveis } \\
\text { presentes nas crianças } \\
\text { podem causar essas } \\
\text { doenças. } \\
\text { - O desinteresse dos } \\
\text { alunos pelas aulas é } \\
\text { grande, eque o professor } \\
\text { de educação física } \\
\text { deverá retroceder esse } \\
\text { processo, através de } \\
\text { suas atividades } \\
\text { realizadas no ambiente } \\
\text { escolar, possa minimizar } \\
\text { os fatores que estão } \\
\text { relacionados com o baixo } \\
\text { rendimento escolar. }\end{array}$ & $\begin{array}{l}\text { Foi possível concluir } \\
\text { que os alunos das } \\
\text { séries iniciais com } \\
\text { baixo rendimento } \\
\text { escolar, } \\
\text { apresentaram um } \\
\text { risco para sobrepeso } \\
\text { corporal, um alto } \\
\text { nível de insatisfação } \\
\text { com a imagem } \\
\text { corporal, uma baixa } \\
\text { motivação e um } \\
\text { grande déficit nos } \\
\text { níveis de atenção. }\end{array}$ \\
\hline $\begin{array}{l}\text { Pansera; } \\
\text { paula; } \\
\text { valentini } \\
\text { (2008). }\end{array}$ & $\begin{array}{lr}\text { Investigar } & 0 \\
\text { desempenho } & \text { de } \\
\text { crianças } & \text { nas } \\
\text { habilidades motoras } \\
\text { fundamentais salto } \\
\text { horizontal, } \\
\text { arremesso } \\
\text { equilíbrio sobre um } \\
\text { pé, no decorrer de } \\
\text { um programa de } \\
\text { Educação Física } \\
\text { regular. }\end{array}$ & $\begin{array}{l}\text { Estágios de } \\
\text { maturidade: em } \\
\text { estágio inicial, } \\
\text { elementar ou } \\
\text { maduro. }\end{array}$ & $\begin{array}{l}\text { Os resultados apontaram } \\
\text { que as crianças com } 4 \text { e } \\
5 \text { anos apresentaram } \\
\text { níveis elementares nas } \\
\text { habilidades motoras, de } \\
\text { encontro com o esperado } \\
\text { para a faixa etária. } \\
\text {-Porém, as crianças com } \\
6 \text { e } 7 \text { anos, também } \\
\text { apresentando níveis } \\
\text { elementares, e nâ } \\
\text { maduros como se } \\
\text { esperava, evidenciaram } \\
\text { atrasos em } \text { seu } \\
\text { desempenho motor. }\end{array}$ & $\begin{array}{l}\text { Embora as crianças } \\
\text { participem } \\
\text { atividades } \\
\text { devidamente } \\
\text { orientadas } \\
\text { profissional } \\
\text { qualificado, por } \\
\text { minutos semanal não } \\
\text { tem sido suficiente } \\
\text { para estimular } \\
\text { adequadamente seu } \\
\text { desenvolvimento } \\
\text { motor. }\end{array}$ \\
\hline $\begin{array}{l}\text { Nobre e } \\
\text { Valentini. } \\
\text { (2016). }\end{array}$ & $\begin{array}{l}\text { Investigar a relação } \\
\text { bidirecional entre as } \\
\text { habilidades motoras } \\
\text { fundamentais (HMF) } \\
\text { de escolares e o } \\
\text { contexto. }\end{array}$ & $\begin{array}{l}\text { Teste of Gross } \\
\text { Motor } \\
\text { Development } 2 \\
\text { (Teste de } \\
\text { Desenvolvimento } \\
\text { Motor Bruto 2). }\end{array}$ & $\begin{array}{l}\text { O foco deste estudo não } \\
\text { foi discutir os resultados } \\
\text { do desenvolvimento } \\
\text { motor das crianças, mas } \\
\text { sim o que conduz a tal } \\
\text { processo e suas } \\
\text { possíveis consequências. } \\
\text {-Entretanto, é preciso } \\
\text { salientar que dos } 59 \\
\text { escolares avaliados, } \\
96,6 \% \text { a } \\
89,8 \% \text { apresentaram } \\
\text { desempenho inferior ao } \\
\text { percentil } 5 \text { (Ulrich,2000) } \\
\text { para habilidades } \\
\text { locomotoras e de controle } \\
\text { de objetos, } \\
\text { respectivamente. }\end{array}$ & $\begin{array}{lr}\text { O modelo processo-- } \\
\text { contexto revela que o } \\
\text { próprio ambiente é } \\
\text { multifatorial. } & \text { Assim, } \\
\text { os atrasos } & \text { motores } \\
\text { identificados } & \text { nos } \\
\text { escolares } & \text { do } \\
\text { semiárido } & \text { ocorrem } \\
\text { como } & \text { uma } \\
\text { consequência de uma } \\
\text { interconexão } \\
\text { sistemas, na qual os } \\
\text { processos proximais } \\
\text { que não ra são } \\
\text { desencadeados } \\
\text { microssistema } \\
\text { afetados são } \\
\text { omissão } & \text { pela } \\
\text { exossistema e } & \text { do } \\
\end{array}$ \\
\hline
\end{tabular}




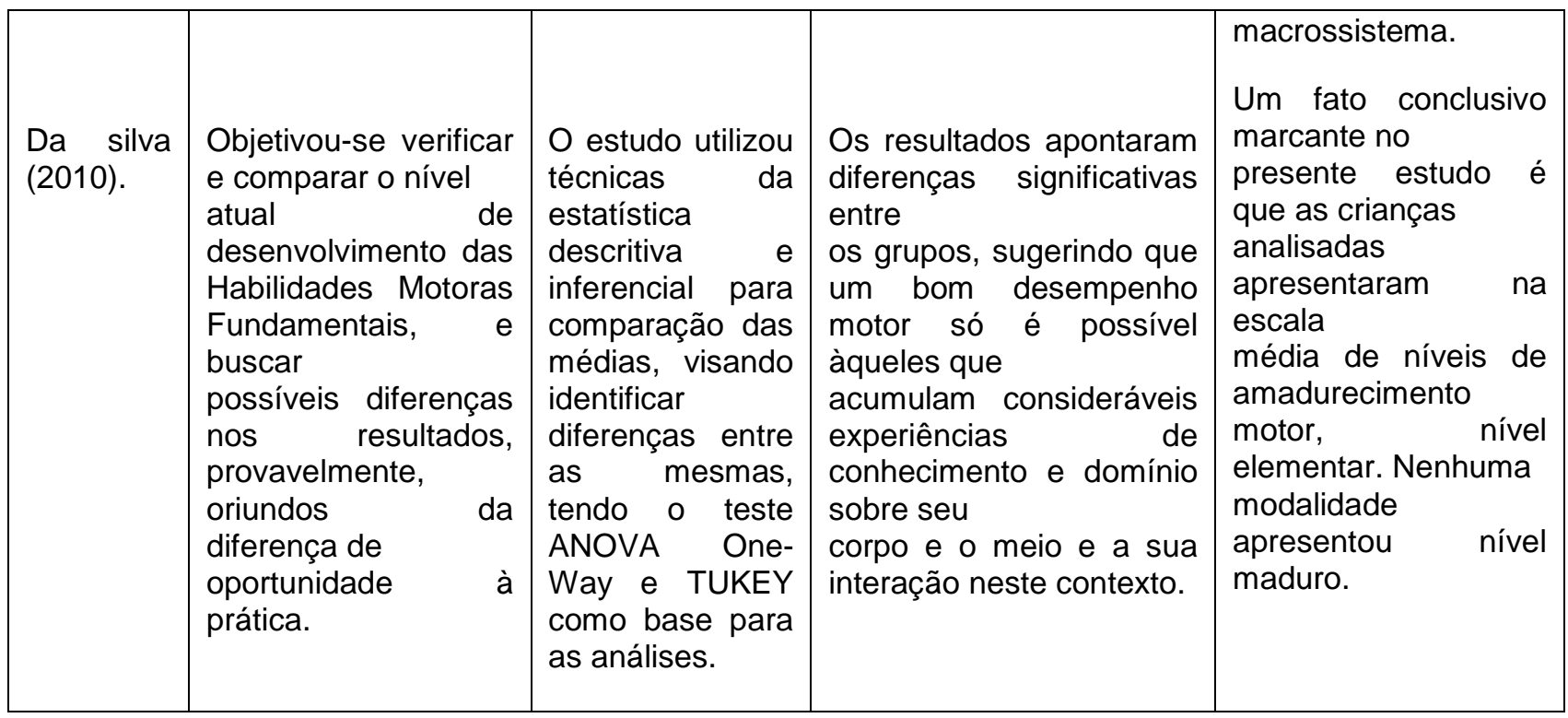

Fonte: SILVA, R. R. S., 2019.

Após a elaboração do Quadro 1 foi possível observar alguns trabalhos que corroboram com o presente estudo, podendo assim discutir que os primeiros anos de vida constituem uma etapa importante do desenvolvimento humano, pois neste período ocorrem progressos em todos os domínios do desenvolvimento em um ritmo muito superior ao de qualquer outra fase da vida (STEIN et al., 2015).

Até os 5 anos de idade as crianças passam por uma evolução no desenvolvimento motor, maior que nos demais anos de vida posteriores, com isso é válido salientar a importância da estimulação do desenvolvimento motor nesse período. Com isso, Pansera; Paula e Valentini (2008), apontaram que as crianças com 4 e 5 anos apresentaram níveis elementares nas habilidades motoras, de encontro com 0 esperado para a faixa etária.

As aulas de educação física como meio para 0 desenvolvimento motor de escolares de 3 a 6 anos se mostrou eficaz, visto que nos resultados encontrados (artigos revisados) as aulas como experiência motora foram positivas para os alunos que tinham essas vivências no ensino infantil. Constatouse a importância da Educação Física como disciplina na Educação Infantil para o desenvolvimento integral da criança. Roweder e Schmitt (2016), por sua vez, falaram que na fase de crescimento citada anteriormente, os aspectos cognitivos, afetivos, motores e sociais da criança precisam ser estimulados. A Educação Física, por meio da ludicidade pode proporcionar ao educando esses estímulos de forma prazerosa e eficaz.

O professor de educação física inserido no ensino infantil se apresentou essencial para 0 aumento e melhora do desenvolvimento motor de escolares, tendo em vista que a presença desse profissional durante todo o período letivo apresentou um aumento em desenvolvimentos de aspectos motores em crianças, com relação a professores que estão atuando fora da sua área. Rodrigues et al., (2013), comentam que no final do ano letivo, crianças que tiveram atividades com 0 professor da sala apresentaram redução no nível de atividade física, enquanto que crianças com aula de educação física com o professor especialista apresentaram manutenção no nível de atividade física e melhor desenvolvimento das habilidades motoras

A partir de aulas de educação física, o desenvolvimento das habilidades motoras seria alcançado em patamares mais elevados. Segundo Rodrigues et al., (2013), acontecendo desenvolvimento motor mais avançado, não haveria necessidade de crianças engajarem em programas especiais de intervenção motora, pois as aulas de educação física já propiciariam estímulos e condições necessárias para o desenvolvimento motor esperado e desejado. Portanto as aulas de educação física no ensino infantil, bem estruturadas e planejadas de forma correta para o ensino aprendizagem dos escolares, favorecem o ganho de habilidades motoras e o aumento da atividade 
física, sendo de grande importância para a prevenção relacionada à saúde e também para 0 desenvolvimento motor dessas crianças. Stein et al., (2015), afirmam que, estudos sugerem que as atividades

\section{CONCLUSÃO}

A proposta do presente estudo foi de identificar o papel do desenvolvimento motor de crianças de a 3 a 6 anos, visando a aplicação da educação física no ensino infantil, e sua importância para a aquisição de aspectos motores nessas crianças. A partir disso foi possível observar a importância da presença das aulas de educação física no ensino infantil, tendo em vista a evidente melhora no desenvolvimento motor dos escolares que tinham aulas de educação física. estruturadas durante as aulas de educação física, podem aumentar os níveis de atividades físicas diárias em pré-escolares, enfatizando a importância dessas aulas nessas idades.

O crescimento no desenvolvimento motor de escolares de 3 a 6 anos de idade no ensino infantil foi maior observado quando houve participação de um profissional de educação física, onde o mesmo através do seu conhecimento na área conseguia criar atividades onde o desenvolvimento motor dessas crianças era mais estimulado. Portanto a educação física inserida na educação infantil pode proporcionar aos alunos um maior desenvolvimento motor, auxiliando cada vez mais no crescimento dos mesmos.

\section{REFERÊNCIAS}

BASEI, A, P. A Educação Física na Educação Infantil: a importância do movimentar-se e suas contribuições no desenvolvimento da criança. Revista Ibero americana de Educación, Madrid, v. 47, n. 3, p. 1-12, 2008.

DA SILVA MELLO, A. et al. Educação física na educação infantil: produção de saberes no cotidiano escolar. Revista Brasileira de Ciências do Esporte, Brasília, v. 36, n. 2, p. 467- 484, 2014.

GALLAHUE, D. L.; OZMUN, J. C.; GOODWAY, J. D. Desenvolvimento Motor: Um Modelo Teórico. In: GALLAHUE, D. L.; OZMUN, J. C.; GOODWAY, J. D. Compreendendo o desenvolvimento motor: bebês, crianças, adolescentes e adultos. 7. ed. Porto Alegre: Amgh, 2013. p. 187-291.

GALLAHUE, D. L.; DONNELLY, F. C. Educação Física Desenvolvimentista para Todas as Crianças. São Paulo, Phorte, 2008.

HAYWOOD, K. M.; GETCHELL, Desenvolvimento Motor ao longo da vida. 5. ed. Artmed, 2010.

NETO, F. R. et al. Desenvolvimento motor de crianças com indicadores de dificuldades na aprendizagem escolar. Revista Brasileira de Ciência e Movimento, Brasília, v. 15, n. 1, p. 45-52, 2008.

NISTA-PICOLLO, V. L.; MOURA, W. W. Corpo em Movimento na Educação Infantil. São Paulo: Cortez, 2012. 1 v. (Educação Física Escolar).

NOBRE, F. S. S; VALENTINI, N. C. O contexto de desenvolvimento motor de escolares do semiárido: contribuições do modelo processo-contexto. Revista Brasileira de Ciências do Esporte, Brasília, v. 38, n. 2, p. 132-138, 2016.

NUNES, L. C. et al. Perfil de estudantes dos anos iniciais com baixo rendimento escolar: importância da educação física na escola. Rev. bras. ciênc. movimento, Brasília, v. 22, n. 2, p. 36-46, 2014.

PANSERA, S. M; DE PAULA, P. R; VALENTINI, N. C. Educação Física no Ensino Infantil: Sua influencia no desempenho das habilidades motoras fundamentais. Cinergis, Santa Cruz do Sul, v. 9, n. 2, p. 25-32, 2008.

RODRIGUES, D. et al. Desenvolvimento motor e crescimento somático de crianças com diferentes contextos no ensino infantil. Motriz, Rio Claro, v. 19, n. 3, p.49-56, set. 2013. 
SARAIVA, L; RODRIGUES, L. P; BARREIROS, J. Adaptação e validação da versão portuguesa Peabody Developmental Motor Scales-2: um estudo com crianças pré-escolares. Revista da Educação Física/UEM, Maringá, v. 22, n. 4, p. 511-521, 2011.

SORATO, M; HUF, T; MIRANDA, S. A importância da Educação Física Escolar. In: CONGRESSO NACIONAL DE EDUCAÇÃO, 9., 2009, Curitiba, Anais [...] Curitiba: PUCPR, p. 01-08, 2009.

STEIN, I. et al. Educação Física na Educação Infantil: uma revisão sistemática. Cinergis, Santa Cruz do Sul, v. 16, n. 4, p. 01-07, 2015.

TANI, Go. Comportamento motor e sua relação com a Educação Física. Brazilian Journal of Motor Behavior, São Paulo, v. 1, n. 1, p. 20-31, nov. 2006.

UGRINOWITSCH, H; BENDA, R. N. Contribuições da Aprendizagem Motora: a prática na intervenção em Educação Física. Rev. Bras. Educação. Fís. Esporte, São Paulo, v. 25, n. 25, p. 25-35, dez. 2011. 